\title{
VALORES CULTURALES E IDENTIDAD NACIONAL EN LARGO HA SIDO ESTE DÍA DE JOSÉ MANUEL CRESPO
}

doi.org/10.15452/SR.2021.21.0007

ORCID ID: 0000-0003-3868-8026

\author{
Luz Stella Hurtado Rúa \\ Universidad del País Vasco \\ España \\ lucero1965806@hotmail.com
}

Resumen. El tema fundamental de esta comunicación es la exposición de algunos de los valores culturales y ciertos rasgos de identidad nacional que muestra la autobiografía Largo ha sido este día (1987), del escritor colombiano José Manuel Crespo. La investigación se realiza a partir del análisis e interpretación de los diversos elementos que componen la obra en las categorías sintáctica, semántica y pragmática y, especialmente, del papel que ejerce la memoria individual y colectiva para la organización del discurso narrativo. Los rasgos expuestos están relacionados con Ciénaga (lugar de nacimiento del autor), en la cual se descubre la importancia del grupo social que rodea el entorno del escritor y la influencia del testimonio oral, además de ciertos vocablos vinculados con la fauna y la flora. Se enlazan dentro del espacio autobiográfico las costumbres y tradiciones de la época expuesta (décadas de los años cuarenta y cincuenta), la adquisición de conocimientos a través del discurso que exponen todos los personajes a los que se alude. El autor manifiesta a través de esta obra, no solamente aspectos personales de su infancia, sino también la trascendencia de la cultura cienaguera cuando evoca rasgos que permiten conocer hechos que inciden en la memoria e identidad nacional.

Palabras clave. Análisis literario. Cultura del Caribe. Identidad nacional. Lenguaje hablado. Literatura latinoamericana. Memoria colectiva.

Abstract. Cultural Values and National Identity in Largo ha sido este día by José Manuel Crespo. The main topic of this paper is the exposition of some of the cultural values and certain characteristics of national identity shown in the autobiography Largo ha sido este día [It's been a long day] (1987), by the Colombian writer José Manuel Crespo. The research is based on 
the analysis and interpretation of the various elements that compose the syntactic, semantic and pragmatic levels of the work and, especially, on the role played by individual and collective memory for the organization of the narrative discourse. The features exposed are related to Ciénaga (the author's birthplace), in which the importance of the social group that surrounds the writer's environment and the influence of oral testimony are discovered, as well as certain words related to fauna and flora. Within the autobiographical space, customs and traditions of the period in question (1940s and 1950s) and the acquisition of knowledge through the discourse exposed by all the characters referred to, are linked. The author manifests through this work not only personal aspects of his childhood, but also the transcendence of the culture of Ciénaga when he evokes features that allow knowing facts that affect national memory and identity.

Keywords. Literary analysis. Caribbean culture. National identity. Spoken language. Latin American literature. Collective memory. 


\section{Introducción}

La investigación de la obra Largo ha sido este día (1987), del escritor colombiano José Manuel Crespo, se realiza para una primera fase de indagación en el Doctorado en Literatura Comparada y Estudios Literarios de la Universidad del País Vasco (España). Interesa la interpretación que hace el autor de su infancia a partir de categorías como el tiempo y la memoria, que no es sólo individual, sino también una memoria social e histórica, lo cual ayuda en la construcción del «Yo» autoral y personal. Es en este sentido que se reflexiona acerca de la delicada relación entre los recuerdos de los acontecimientos del pasado, signados por diferentes aspectos sociales, históricos, culturales y religiosos, partiendo el autor de un estilo muy propio, y actualizando ese pasado histórico a la luz de un trabajo crítico intelectual y su vinculación con el presente.

El marco teórico se compone a partir de diversos estudiosos de la autobiografía, la memoria y la novela lírica que están, algunos de ellos, referenciados en el presente artículo. La lectura de esos teóricos se presenta como una ayuda para la interpretación de la obra en cuestión, pues proporciona herramientas teórico-metodológicas y las ideas necesarias para examinar y describir los elementos del discurso narrativo a partir de las categorías sintáctica, semántica y pragmática, lo cual contribuye con la formulación de las distintas características.

El desarrollo metodológico está basado en fuentes documentales y sus análisis, que son el principal depósito de información, además de la presentación de una entrevista que fue realizada al autor y un grupo de fotografías que refieren, especialmente, elementos del «espacio» de la obra de análisis, que fueron tomadas por la investigadora para complementar el trabajo; por otra parte, se organizan ayudas para la difusión de la obra del autor en varias redes sociales. ${ }^{1} \mathrm{Al}$ ser un trabajo tan extenso, la presente comunicación refiere solamente algunos de los rasgos vinculados con la identidad nacional y los valores culturales presentes en esta obra, debido al papel de la memoria individual y colectiva. Por tanto, el objetivo primordial es identificar algunos de esos aspectos, para lo cual se emplea la exposición de determinadas citas textuales de la obra que los refieren.

José Manuel Crespo (1942-2020) nació en Ciénaga (Magdalena), en donde vive sus primeros diez años de vida, los cuales relata en esta autobiografía, vivencias que serán recordadas toda la vida por el autor. Ciénaga es la segunda ciudad del departamento del Magdalena y está localizada a orillas del Mar Caribe, en la Costa Atlántica, junto a la Sierra Nevada de Santa Marta (Colombia). Existe desde antes del descubrimiento de América, era una aldea aborigen cuando fue catequizada por Fray Tomás Ortiz en 1538. Sus ancestrales tradiciones musicales y sus celebraciones la han caracterizado por siglos y, también, ha sido escenario de importantes hechos en la historia del país, como el enfrentamiento entre patriotas y realistas en la batalla de Ciénaga el 10 de noviembre de 1820 y la «Masacre de las Bananeras», el 6 de diciembre de 1928.

Crespo muestra acontecimientos de la cultura de esta población colombiana, los factores que contextualizan su infancia, permitiendo alcanzar lo acaecido en años anteriores a su nacimiento, durante su infancia y, a su vez, sucesos posteriores que se integran en la trama de la memoria nacional.

1 Véanse las referencias bibliográficas relacionadas con la autora del artículo. 


\section{Memoria individual y colectiva}

Francisco Puertas (2004: 30) afirma que: «La memoria es la que nos permite darnos cuenta, ser conscientes y tener conciencia, la que nos obliga a ser entes autobiográficos volcados hacia nosotros mismos, a nuestro pasado, a lo que de él queda en el presente de una reconstrucción que sólo la memoria asegura y hace posible». Gracias a la memoria, se da una realización del entorno social, pues se mantiene la identidad cultural debido a la capacidad de aprendizaje que se representa en ella. Otros autores profundizan en ello, como Ángel Loureiro (1991: 3), quien expone que «la memoria actúa como redentora del pasado al convertirlo en un presente eterno», o como José M. Pozuelos Yvancos (2006: 87): «la memoria autobiográfica es pasado presente».

Para que la reconstrucción del pasado sea posible ha de intervenir la «memoria», pues el escritor, frente a la página en blanco, cierra sus ojos y evoca sus recuerdos, hace una retrospección que le permite rescatar de ella lo más importante, valioso y esencial, bien sea por un camino objetivo de su conciencia cognoscente o por un camino incontrolado y automático de su inconsciente que hace que su memoria se active. Los diversos tiempos y lenguajes que en la sociedad se manifiestan posibilitan que la memoria se edifique, que se contenga, pero para mantenerla es necesario comunicarla de alguna forma. Si la memoria quiere perdurar, no caer en el olvido, requiere comunicarse para tener receptores que se interesen en perpetuar ciertos acontecimientos que les permitan reconocerse en ellos, como lo plantea Marc Augé (1998: 28): «El olvido, en suma, es la fuerza viva de la memoria y el recuerdo es el producto de esta». José Manuel Crespo (1987) lo expone en su autobiografía, cuando hace relación a este olvido en el tiempo y la memoria:

$\mathrm{Y}$ así como en un teatro se apagan suavemente las luces para cambiar el decorado, en mi recuerdo pasan y se suceden las voces, las presencias, las miradas y hasta se me confunden los olvidos (en este preciso instante no se me viene el nombre de unas flores color malva que no se abrían sino en octubre) pero sigue y prosigue en mi memoria el olor de esta casa donde una tarde vino a cerrar un negocio con mi abuelo un hombre alto, risueño y de maneras afables pero que, a ratos, [...] rencores, luchas (Crespo, 1987: 17).

Paul Ricoeur (1999: 79), en su relación a los hechos y huellas ocurridas en el pasado, plantea que: «El testimonio introduce una dimensión lingüística ausente en la metáfora de la señal o de la marca, a saber, el discurso del testigo que cuenta lo que ha visto y requiere ser creído». Crespo es un testigo, abre ventanas para dirigir una mirada hacia el mundo, vuelve a su interioridad a fin de descubrir textos posibles, consciente de que un lenguaje nuevo lo habita, y sabe que la escritura es una manera viva de ser su yo, de construir su vida, de dejar testimonio. Cuando se relaciona la memoria colectiva, Ricoeur expone que el hecho más importante consiste en que uno no recuerda solo, sino con la ayuda de los recuerdos de otros, y concluye que «la memoria colectiva sólo consiste en el conjunto de las huellas dejadas por los acontecimientos que han afectado al curso de la historia de los grupos implicados que tienen la capacidad de poner en escena esos recuerdos comunes con motivo de las fiestas, los ritos y las celebraciones públicas» (Ricoeur, 1999: 19). El discurso crespiano aprovecha la memoria individual y colectiva, creando 
un espacio autobiográfico que aparte de descubrir aspectos personales del autor, revela diversos rasgos culturales.

Según Philippe Lejeune (1991), el espacio autobiográfico se crea allí donde se alojan los deseos de los escritores (aun en las obras de ficción) para que se lea la verdad de su escritura y por ende de su vida, y para Crespo es en Ciénaga en donde se alojan sus deseos, pues se muestra lleno de reflexiones sobre esta, de silencios reactualizados de su pasado que reflejan valores culturales e identidad nacional: «Ciénaga no era más que un polvoriento espejismo junto a su mar, su lago y su montaña, una pequeñez, una brisita de ciudad que iba viviendo del pescado, las frutas y los sueños en medio de ese clima que les volvía las uñas de cristal a los muertos» (Crespo, 1987: 105).

En Ciénaga están el Puerto de las Mercedes, los barrios Cachimbero y los Palmares, bares como el Cabo verde, entre otros, y las viviendas de sus habitantes, en donde ocurrieron hechos que modificaron el diario vivir de sus pobladores, pero el transcurrir de su existencia es mucho más que la descripción de situaciones en los espacios que están dentro o fuera de ella misma. Su visión de Ciénaga es la de una población que, paulatinamente, se ha hecho en sus recuerdos, amable, tierna, benévola, alucinante, deslumbrante, única, lo que la hace realmente interesante: «Ciénaga, por momentos, se quedaba sin aire, vencida, quieta, paralizada en un vacío que afilaba las largas ramas de los tamarindos en esa calma inflamada por el verano en que furtivamente se percibía el resuello del mar» (Crespo, 1987: 102).

Otros lugares que reinciden en sus recuerdos son, entre otros, la Sierra Nevada de Santa Marta, los ríos Córdoba y Atrato, poblaciones como Santo Domingo, islas como Guadalupe y Guanahani y, especialmente, las playas y el mar. Más de doscientos lugares en la obra exponen una minuciosa evocación que al ser de tantos ámbitos pareciera situar al lector por momentos en el entorno de una geografía imaginaria.

La memoria social en Crespo, respecto del pasado analizado, toca varios puntos centrales: el deber de la memoria frente al olvido, al silencio y a la construcción de su vida a partir de aspectos externos como lo son Ciénaga y su cultura. Es interesante observar sus reflexiones sobre las estrategias de algunos de sus personajes (los cienagueros), en cuanto a la aprehensión de determinados elementos de su cultura, centrándose en las formas de transmisión de los aspectos culturales y simbólicos, estrategias que constituyen instancias claves para la reproducción cultural y, al entender de la investigadora, en la cristalización de lugares de la memoria colectiva y de la identidad individual. Lo que interesa remarcar en este sentido es que lo que está puesto en cuestión es la identidad de la sociedad, ya que cuando el grupo no se interesa más por la memoria, pierde su propia identidad.

La memoria es elaborada, reproducida y resignificada con el fin de generar conocimientos de su pasado. «A veces, nos limitamos a señalar que nuestro pasado incluye dos clases de elementos: aquellos que podemos evocar cuando queremos y aquellos que, al contrario, no obedecen a nuestro llamado, de modo que, cuando los buscamos en el pasado, parece que nuestra voluntad choca con un obstáculo» (Halbwachs, 2010: 86). La presencia de la memoria colectiva se trasluce en las prácticas y voces de Crespo cuando las incorpora a su discurso, por lo que observar las manifestaciones de la cultura y la actualización de la memoria efectuada mediante 
la oralidad, permite el abordaje de esta. En efecto, el recurso a la historia oral que toma Crespo es fundamental, ya que el «testimonio oral» aparece como un documento histórico, que tiende a colocar la estructura de la mentalidad individual en el horizonte de una historia social vivida, permitiendo conocer la historia del grupo desde la cotidianidad del sujeto, pues se ve cómo recurre a lo que les sucede a terceras personas que cuentan sobre lo que le ocurrió a otra persona. Un ejemplo de ello sería: «nos dijo Uriel Acosta que su padre contaba que su abuelo decía que aquellos hombres de rompe y rasga capaces de robarle hasta la luz del sol a los pendejos que se les dejaran y que se imaginaban [...] para el mundo» (Crespo, 1987: 222). No es extraño, entonces, encontrar a una mujer que cuenta sobre otra que cuenta lo que un hombre narra acerca de las historias de héroes, guerras, odios:

Mariana Campo contaba que Luisa Riascos relataba que su padre le había oído recordar al negro Laches ese miércoles de ceniza en que un hombre cubierto con una túnica andrajosa se apareció en la Calle de las acacias precedido por tres niños que llevaban una cruz de madera burda y dos espigas y algo como un susurro de temor que [...] y broches de zafiro» (Crespo, 1987: 213).

Una de las formas de guardar los recuerdos proviene del lenguaje: este aumenta la amplitud de la memoria. Ciertamente, las convenciones lingüísticas y las palabras que el autor presenta tienen un poder evocador y proporcionan el sentido de lo evocado. Crespo se sirve de la palabra para hacerse a sí mismo, para permanecer, para construir identidad. Utiliza vocablos poco conocidos que identifican la botánica y la naturaleza de la zona, palabras que aprende desde niño, y que se pueden encontrar en el diccionario de la Real Academia Española, ahora con la ASALE (23a ed.). Ciertos ejemplos son: esqueje (tallo o cogollo que se introduce en tierra para reproducir la planta), adelfa (arbusto de la familia de las apocináceas, muy ramoso, de hojas persistentes semejantes a las del laurel, y grupos de flores blancas, rojizas, róseas o amarillas. Es venenoso y florece en verano), nelumbo (planta ninfeácea, de flores blancas o amarillas y de hojas aovadas), carañas (resina medicinal de ciertos arboles gutíferos americanos, sólida, quebradiza, gris amarillenta, algo lustrosa y de mal olor; nombre de algunas especies de árboles de variado tamaño, de la familia de las burseráceas), entre otras, y en ese sentido se podrían llenar páginas completas de términos referentes a esta temática, como muestra este fragmento:

Mi abuelo sostenía que los muchachos debían conocer mejor las matas del patio de su casa [...]. Aún asocio su recuerdo con los poderes y los nombres de una botánica secreta (la Ceiba bruja, la malva, la contragavilana, el orozul, la salvialugo, el tártaro colorado, el mastranto, la verbena negra, la plumaria colorada, el mirto de la cera, el jazmín atigrado, la escubilla menuda, el bencenuco, la caléndula, el merey, la celedonia) y con aquellas narraciones contadas en una lengua salvaje en las que la tristeza y maravilla estaban en que me describían ese universo borrado en pleno génesis por un súbito apocalipsis que salía de las olas, un mundo que sin pausas ni transiciones pasaba de las manos de Dios a las pezuñas de los potros que venían de más allá de la línea (Crespo, 1987: 71).

También se hallan localismos como: caneyes (cobertizos con techo de palma o paja, sin paredes y sostenido por horcones), zampoñas (instrumento rustico, a modo de flauta, o compuesto de muchas flautas; flautilla de la caña del alcacer), transmitiendo su significado dentro del contex- 
to lingüístico aun para quienes no las conocen. De igual manera, se descubren otros localismos que no son encontrados en el diccionario de la RAE y ASALE, haciendo relación al lugar donde vivió su infancia como: yolofos (pájaros de la sierra nevada de Santa Marta), vagalumes (luciérnagas, cocuyos, candelillas), musengue (especie de abanico hecho de cogollos de palma), caracuríes (caracolitos), paraco (nidos de avispas), moyones (pozos o remansos hondos de los ríos), guandolo (guarapo de caña). Todas las anteriores significaciones se toman de diversas páginas en línea relacionadas con la región del Caribe y/o con la botánica y fauna del espacio de la obra (Ciénaga). ${ }^{2}$

La individualidad crespiana se sume en lo colectivo, su familia, amigos, gente allegada y, por ello, no hay recuerdo estrictamente individual, todo está conectado. Las aproximaciones en torno al plano social de los cienagueros manifiestan la evocación de la vida del autor, quien hace detalladas descripciones de espacios de sociabilidad. El papel de su madre, por ejemplo, refleja de alguna manera el rol de las mujeres de esa época en Ciénaga, dedicadas al hogar, la crianza y cuidado de sus hijos, la atención de sus esposos:

Mi madre iba sirviendo platicos de coco rallado y miel de abejas mientras mi padre y sus amigos hablaban de Citurna (así llamaban los tayronas a la Sierra Nevada), esa tierra donde proliferaba el perro mudo y donde las tribus que vivían dispersas por los montes y les decían palmeras bobas (porque no daban frutos) a los helechos gigantes, [...] y las guabinas de los Andes» (Crespo, 1987: 111).

La influencia de su padre vislumbra la cara poética, histórica y cultural de Ciénaga. A su lado aprendió sobre los grandes poetas españoles, sobre la historia regional y nacional, le oyó historias y leyendas que liberaron su imaginación, lo acompañó en sus caminares, como se descubre en la siguiente cita:

Andando con mi padre por esas plantaciones de Orihueca, Tucurinda y Riofrío conocí campesinos que tocando los anillos de crecimiento de los árboles podían determinar la edad de un bosque y observando las vetas de los troncos envejecidos por las brisas, los soles y las lluvias, sabían decir el año y casi el día en que las rulas de los colonos habían talado un roble (Crespo, 1987: 21).

Igualmente, detalla en sus más de ciento sesenta personajes reales (padres, hermanas, familia cercana y vecinos del pueblo) y más de doscientos cincuenta personajes referenciales (históricos, religiosos, míticos, etc.), los hábitos de trabajo, los elementos del imaginario social, las fiestas y costumbres propias de un pueblo costero. Crespo reflexiona, describe y revive la información sobre cómo los cienagueros transcurren su vida hábilmente entre el pasado y el presente. Por medio de estos personajes se observa la manera de vivir y padecer de una población desde sus orígenes antes de la llegada de los españoles hasta después de los años cincuenta del siglo XX, puesto que se refieren sucesos que marcaron la propia identidad de la zona.

Algunos de los personajes históricos que se descubren en la obra contribuyen con la construcción de una nueva Colombia o, por el contrario, la dominación o tiranización de ella:

2 https://lenguasdecolombia.caroycuervo.gov.co/contenido/Espanol-de-colombia/Articulo/ contenido/1388 
Cristóbal Colón, descubridor de América en el siglo XV; Rodrigo de Bastidas y Vasco Núñez de Balboa, conquistadores españoles en el siglo XVI; Simón Bolívar, libertario de la opresión colonizadora española en el siglo XIX; José Prudencio Padilla, oficial del ejército colombiano del siglo XIX; y otros personajes históricos universales, como François Dominique Toussaint-Louverture, político y militar, dirigente de la Revolución haitiana; Rafael Leónidas Trujillo Molina, militar y dictador dominicano en el siglo XX; tribus indígenas como los tayronas, los pocigueicas, los wayuú y los mayas. Se asiste, a partir de su escritura, al desmoronamiento de una época dominada por la superstición, cuando la barbarie y los afanes de poder devoran la fuerza de los pueblos, pero también a la afirmación, comprensión, la visión y proyección de los pensadores, creadores, agitadores y detractores. De igual manera, el destino del autor no hubiera podido proyectarse en el tiempo sin haber vivido o escuchado los acontecimientos de muchos personajes cercanos sobre, por ejemplo, la guerra civil, los odios partidistas, la intolerancia religiosa y todo lo que ha acompañado a la sociedad colombiana en siglos de historia colonizada y de independencia.

Las memorias individuales son parte de las colectivas, son memorias de memorias relacionadas comunicativamente; los recuerdos que no se piensan o no se comunican tienden a perderse, se vuelven olvido social, y la sociedad, comunicativamente hablando, se empequeñece porque, entonces, su pasado se ve empobrecido. El componente cultural y social influyó comportamientos en su niñez y lo mítico obró trascendental importancia. En palabras de Claude Lévi-Strauss (1964: 49), «el mito utiliza una estructura para producir un objeto absoluto que ofrezca el aspecto de un conjunto de acontecimientos (puesto que todo mito cuenta una historia)». Con Crespo los mitos ofrecen su valor principal preservando hasta nuestra época los modos de observación y reflexión que estuvieron, y siguen estando, adaptados a descubrimientos de un cierto tipo, sobre todo de la naturaleza y su organización del mundo sensible.

Se describe en varios capítulos el carácter mítico y sagrado sobre los orígenes del hombre y la tierra, por parte de los grupos indígenas y los de aspecto religioso presentes en la Biblia. La influencia social, cultural del pueblo donde nació se remonta a comunidades indígenas (los de la Sierra Nevada, los arahuacos, entre otros), las que nombra en varias ocasiones en su texto para referir sus costumbres. Estas culturas indígenas cargan de significación los seres que perciben y los clasifican de acuerdo con los conocimientos que adquieren, por lo que las plantas, animales y rituales prevalecen con el tiempo y, después de la colonización, muchos de estos mitos y ritos quedan adheridos a las nuevas sociedades, que son metódicas y están fundadas en un saber teórico sólidamente armado por ellos. La tradición oral, las costumbres de vida de las que Crespo siempre estuvo rodeado, colaboran, por tanto, en su niñez, en el descubrimiento y conocimiento de mitos que luego se encargaría de exponer en su texto:

Así, por el espejo de los juegos, las mujeres, las muertes, los asombros, y el saboreo de los nísperos, me fui metiendo en la materia cienaguera y Caribe de los mitos y de tanto abandonarme a los ímpetus oscuros de esa poesía feroz y delicada, soñadora y errante, se me fue perdiendo el alma en un periplo antillano que marcaría para siempre mi espíritu. El mar me hizo a su aire (Crespo, 1987: 16). 
Son tantas las historias míticas que enuncia, que de pronto parece quedarse atrapado por ellas. Si se quisiera investigar el origen de estas historias sería necesario extenderse a siglos de vida de los hombres. He aquí una de las tantas historias relacionadas con algunos mitos que se encuentran en la autobiografía, como la del «Mohán», que también se encuentran en otras zonas de Colombia:

De los vallecitos perdidos de la Sierra Nevada donde existían ciudades fabulosas y ruinas iluminadas que aparecían de noche ante los ojos de los caminantes pero que se iban desapareciendo a medida que los extraños se les aproximaban; de rocas misteriosas en que una tribu de sangre verde que vino huyendo de las heladas había grabado helechos, entalladuras y volutas vegetales; de las colinas de San Pedro de la Sierra donde después de las tormentas empezaban a relucir en el barro unas lentejuelitas de oro lavadas por el aguacero que los indios decían que se formaban en el instante en que la tierra y la luz prodigiosa se tocaban y les decían virutas del arco iris pero alguien repetía que quien formaba las pepitas de oro no era la luz sino el mohán porque donde se encuentra el arco iris es fijo que se encuentra «el compadre» y ese recuerdo iba prendiendo una discutidera interminable sobre si el mohán era un hombre alto, de ojos azules y cabellera verde o si era un negro chiquitico que salía brincando por las espumas en medio de las crecientes aunque Libardo Arguedas (un forastero que usaba sombrero suaza y que venía de las montañas donde le dicen la nevazón a la lluvia) argumentaba que el mohán no vivía en los moyones hondos de los ríos sino en los nichos y socavones de los cerros pero en verano le gustaba calentarse en las piedras lo mismo que los lagartos y pasearse desnudo por sembríos y en las horas en que se salía de su cueva para irse a los pueblos a comprar piola de atarrayas, fósforo y tabaco (pero sal no compraba nunca) era cuando sobrevenían esas crecidas en las que se desataban las corrientes y se desbordaban las cuencas poderosas del agua y que si un pescador decía en voz alta que «el compadre» no existía, el mohán se convertía en un tronco para voltearle el cayuco, le espantaba los bagres y palometas, cargaba con los pelaos o le seducía las hijas sacando pescaditos de colores que las niñas intentaban seguir y se las iba llevando a lo profundo de los aguares, [...] por el aire que iba convirtiéndose en brisa (Crespo, 1987: 23).

Como lo afirma Álvaro Pineda Botero (1987: 6), al referirse a esta obra: «Cuando habla de los mitos, en un solo párrafo aparecen desde el de la fuente de la eterna juventud y el del paraíso hasta los de los indígenas de la Sierra y los del corazón africano». El mito, con sus imágenes y con la ayuda de otro/s busca intentar ponerse fecha, situarse, relacionarse y, en fin, convertirse en relato.

Asimismo, la autobiografía registra pasajes que manifiestan la inserción de lo religioso como aspecto esencial en la construcción de la personalidad del escritor, pues se observa, por ejemplo, cómo sus conocimientos bíblicos van más allá de la simple citación de versículos, ya que se muestran análisis e interpretaciones de estos:

Caín fue el primer hombre engendrado después de la caída, cuando la ira de Dios era una brasa y el temor y la culpa supuraban en la conciencia de los padres. Abel nació más tarde, cuando Adán conocía la penitencia y Dios la misericordia. Caín fue concebido a la sombra del árbol de la ciencia (de ahí que sus descendientes levantaran ciudades, trabajaran metales y construyeran cítaras y flautas) y Abel en esas noches en que la trágica pareja se amaba con la esperanza de re-encontrar el árbol de la vida (Crespo, 1987: 146). 
Son más de cien personajes referenciales pertenecientes a la Biblia, entre ellos, el patrono o santo religioso de Ciénaga, San Juan Bautista. La religión hace parte de la vida en Ciénaga y, por tanto, de los personajes que allí habitan, por lo que hay referencia a las procesiones, las fiestas y las celebraciones de sus habitantes. El diablo, las Vírgenes, los santos, las santas, los demonios, los personajes bíblicos que contribuyeron a revelar la palabra de Dios, los dioses de los pueblos indígenas, reminiscencias árabes, evocaciones de un pasado católico que nunca deja de reconfigurarse en su narración y que incide en la conciencia moral de Crespo formada y construida en su pueblo natal.

En sus recuerdos y en su vida, Crespo se sabe creyente y traslada a su narración todo ese componente que le deja respirar día a día: «en esa tierra donde los contrabandistas afirmaban que Dios había hecho el cielo para quien le sirviese y la tierra y la plata para quien más pudiese» (Crespo, 1987: 196). Da una significación especial a lo religioso como experiencia personal, relacionada con su entorno familiar, eclesial, escolar, social, que se da en términos de actitudes, creencias y prácticas. En su contexto familiar se daba mucha importancia a la formación cristiana, por lo que las prácticas y costumbres católicas hacían parte de su cotidianidad, que implicaba ritos y fiestas religiosas; por ejemplo, no se faltaba con el bautismo después de que un niño naciera, ir a misa todos los domingos, asistir a los velorios y un sinfín de creencias, conocimientos y rituales dados por la Iglesia.

Los personajes en Ciénaga tienen un mundo a su medida, las narraciones se desenvuelven (o mejor, se enredan y enmarañan) en un ambiente de pueblo primordialmente. A través del texto, el lector experimenta las sensaciones vividas por Crespo en los diferentes espacios debido al modo en que están escritas, a la puesta en forma, y a los rasgos de esos espacios detallados:

Los notables y el pueblo se reunieron en el salón de los siete candelabros una tarde en que los almendros de Aldea Grande se fueron recubriendo de unas bandadas de pájaros negros y anaranjados que venían de las olas y que los marineros decían que en Tampa los llamaban los orioles de Baltimore, [...] combatía por la victoria (Crespo, 1987: 163).

Igualmente, se descubren otros rasgos culturales como la música, a la cual hace referencia por su riqueza en la zona atlántica.

Bien puede aseverarse que el pensamiento y, por tanto, la escritura crespiana se va formando de la cultura que se encuentra a su paso, como lo plantea Agnes Heller (2003: 5). «La memoria cultural está conformada por objetivaciones que proveen significados de una manera concentrada, significados compartidos por un grupo de personas que los dan por asumidos». El pensamiento crespiano deriva de la comunicación, del contacto social, de la influencia del medio y, de algún modo, refleja propiedades del dialogo externo, del hablado. El aprendizaje internalizado que se da constituye una práctica en la que Crespo se forma a partir de los elementos que brindan aquellos de quienes se rodea, conjugando diversos elementos de los grupos y comunidades distintas a las que pertenece. De forma similar Nancy Malaver Cruz (2013: 41) expone que: «Es tal el poder de la literatura en la construcción del recuerdo y del olvido, que se puede afirmar que ella tiene una profunda conexión con el desarrollo mismo de la civilización». 


\section{Conclusiones}

Todos los elementos que hacen parte de la cultural nacional se descubren en esta obra: las tradiciones, el lenguaje, los mitos, las costumbres sociales que incluyen la gastronomía, las fiestas y celebraciones, la música, la Historia, además de un espacio que muestra los animales y la vegetación típica de la zona atlántica. Con Crespo, todo es aquí y ahora, todo es posible porque existe la memoria. El sentido de totalidad se alcanza sin prescindir de ninguna de las dimensiones de la conciencia y, por tanto, de la vida: el paisaje, la reflexión sobre la historia y la religión, el tiempo pasado y el presente más inmediato.

Es necesario recuperar la memoria, porque lo que se hace sin memoria constituye un mundo ambivalente. Si la memoria quiere perdurar, no caer en el olvido, requiere comunicarse para tener receptores que se interesen en perpetuar ciertos acontecimientos que permitan reconocerse en ellos. En el espacio crespiano cada calle, lugar, o acontecimiento que se describe, recuerda las vivencias que el autor experimentó en Ciénaga, pues se presenta su importancia e incidencia para la formación del autor.

A causa de su pasión por la existencia humana, por este mundo y por la palabra, ha alcanzado, según esta investigadora, como los místicos, una profunda sabiduría que se expresa en todos sus textos. Crespo es un hombre siempre dispuesto a reivindicar la verdad y la vida humana, pasando por temas tan diversos como el arte, la música, la cultura, la historia y el mito, y por elementos que los integran como las plantas, flores y animales, entre otros. En lo básico de toda su obra, sus aportes históricos y culturales no son menores que sus cualidades literarias.

Esta autobiografía deja huella clara de la memoria nacional, puesto que expresa la historia de la cultura cienaguera, sus angustias y encantos. La repercusión que Crespo proyecta en su texto es enorme, ya que abarca elementos que merecen ser estudiados por quienes ya los conocen y por quienes estén interesados en profundizar en la literatura, historia y cultura nacional. Esta obra es una reflexión, no sólo de los recuerdos que aquejaron el alma del autor y todos los interrogantes e impresiones que tuvo de niño, sino que, también, es sobre la cuestión espiritual, desgarrada, visceral de hombres y mujeres que se preguntan y asombran siempre por los grandes interrogantes metafísicos de la existencia. No cumple únicamente la función de evocar con nostalgia la infancia, es, además, el objeto ideal para enseñar las costumbres y cultura de los cienagueros. Crespo amplía las posibilidades significativas de este espacio por el peculiar marco de referencias culturales que explicita. Por último, cabe agregar que hay en el texto reflexiones de carácter ético, estético y social a través de la realización y la evocación de las acciones de personajes que sirven de pretexto para cuestionar situaciones de la realidad actual.

\section{Bibliografía}

\ AUGÉ, Marc (1998). Las formas del olvido. Barcelona: Geodisa.

\ CRESPO, José Manuel (1987). Largo ha sido este día. Bogotá: Plaza y Janés.

$\checkmark$ HALBWACHS, Maurice (2010). La memoria colectiva. Buenos Aires: Miño y Dávila.

y HELlER, Agnes (2003). Memoria cultural, identidad y sociedad civil. https://n9.cl/bnq5 [18-04-2012] 
У LEJeune, Philippe (1991). «El pacto autobiográfico». Suplementos Anthropos 29, pp. 47-61.

У LÉvi-STRAuss, Claude (1964). El pensamiento salvaje. México: Fondo de Cultura Económica.

\ LOUREIRo, Ángel G. (1991). «Problemas teóricos de la autobiografía». Suplementos Anthropos 29, pp. 2-6.

У MALAVER CRUZ, Nancy (2013). «Literatura, historia y memoria». Hallazgos 20/10, pp. 35-47.

У PINEDA BOtero, Álvaro (1987). «La Biblia Cienaguera». El Heraldo 30/8/1987, p. 6.

У POzuelo yvancos, José M. (2006). De la autobiografía. Teoría y estilos. Barcelona: Crítica.

У PUERTAS MOYA, Francisco E. (2004). Aproximación semiótica a los rasgos generales de la escritura autobiográfica. Logroño: Universidad de la Rioja.

У REAl ACAdEmia española y ASAle. Diccionario de la lengua española, 23a ed., [versión 23.3 en línea]. https://dle.rae.es [15-10-2021].

У RICOEUR, Paul (1999). La lectura del tiempo pasado: memoria y olvido. Madrid: Universidad Autónoma de Madrid.

\section{Luz Stella Hurtado Rúa}

Senda Valentín de Foronda 12 2B

01010 VITORIA-GASTEIZ (Álava)

España 